\title{
Theoretical design of yttrium oxyhydrides: Remarkable richness of phase diagram
}

\author{
Aleksandr Pishtshev, ${ }^{*} \dagger$ Evgenii Strugovshchikov, ${ }^{\dagger}$ and Smagul Karazhanov ${ }^{\ddagger}$ \\ $\dagger$ Institute of Physics, University of Tartu, Tartu, Estonia \\ $\ddagger$ Department for Solar Energy, Institute for Energy Technology, Kjeller, Norway \\ E-mail: aleksandr.pishtshev@ut.ee
}

\begin{abstract}
The synthesis of stable yttrium oxyhydride-type compounds raised a question regarding the key factors that may be responsible for formation routes and structural features of these attractive materials. For solving this problem the interplay of chemical composition and crystalline architectures has been theoretically explored in terms of possible structural transformations caused by the gradual oxidation of the host metalhydride system. The combination of group-theory methods, mixed-anion chemistry arguments, and relevant DFT calculations provided us with the opportunity to predict and characterize the candidate models for most probable stoichiometric versions of yttrium oxyhydrides. The predicted chemical compositions along with the crystallization results have been summarized in the phase diagram. It is shown that structural stability is achieved by matching favorable crystallographic positions of the nearest oxygen and hydrogen atoms at the metal center.
\end{abstract}




\section{Introduction}

Recently, a strong effect of the reversible switching of optical properties in a response to illumination has been observed in thin films of incompletely oxidized yttrium- ${ }^{1-5}$ and several rare-earth- $(\mathrm{Gd}, \mathrm{Dy} \text {, and Er })^{6}$ hydride systems. A crystal chemical classification of the photochromic oxygen-containing hydride films relates them to advanced multianion materials called oxyhydrides ${ }^{7}$ in which oxide and hydride anions are sharing the common chemical space within the crystal lattice. Further examination of experimental data on yttrium oxyhydrides raised a question of which factors of the oxidation process may promote a crystallization process and which variables may control the formation of solid phases with the different chemical compositions. One can suggest that the differences between crystallization variables are caused by the local configuration of oxide and hydride anions around the metal center. In assembly of a mixed-anion compound, such configuration may offer a certain flexibility of valence charge states of the metal center in regulation of the $\mathrm{H}^{-} / \mathrm{O}^{2-}$ exchange-ability. We will consider this feature as playing a key role in the formation of stoichiometric versions of oxyhydrides and the emergence of stability. We further assume that there is no loss of generality in supposing that the mixed yttrium-hydrogen-oxygen crystalline superstructure can be chosen as a starting periodic system for the simulation of experimental situations. Theoretical investigation of the oxygen chemical evolution in such system has advantages in the sense that it allows us to evaluate the formation of several structural frameworks more straightforwardly in terms of anion orderings. Thus, the main objective of the present work is to model from first-principles in which way the inserted oxygen may govern the spatial separation of the $\mathrm{Y}-\mathrm{H}$ and $\mathrm{Y}-\mathrm{O}$ bonding channels to afford a set of stable lattice geometries. Our goal is to determine evolutionary structural trend that could generate a number of ternary systems depending on the $\mathrm{O}^{2-} / \mathrm{H}^{-}$anion ratio. 


\section{Results and discussion}

The simulation model of the present work follows the general scheme of crystal structure prediction developed in previous works ${ }^{8}$ of Pishtshev and co-workers. To explore anion exchange routes in terms of evolutionary structural transformations the chemical space was projected onto a cubic crystallographic space spanned by yttrium, hydrogen, and oxygen. As a result, a fully functional high-symmetry prototype superstructure has been created. A lot of sites and interstitials makes its three-dimensional periodic lattice a useful starting template for the simulation of possible atomic arrangements in the course of model oxidation. This in turn allows one to directly manipulate the $\mathrm{O} / \mathrm{H}$ stoichiometric ratio in order to test a range of lattice configurations with different compositions.

Table 1: Overview of the predicted crystal chemical parameters of 13 structures in which the initial $\mathrm{Y}-\mathrm{H}-\mathrm{O}$ system may crystallize. Collation order corresponds to numbering of the compounds presented in Figure 1 . In the last column, the quantity $\Delta E$ denotes the formation energy which corresponds to energetics of decomposition reaction on the constituting elements.

\begin{tabular}{|c|c|c|c|c|c|c|c|c|c|c|c|}
\hline \multirow{2}{*}{\multicolumn{2}{|c|}{$\begin{array}{l}\text { No Chem. } \\
\text { formula }\end{array}$}} & \multirow{2}{*}{$\begin{array}{l}\text { Space } \\
\text { group }\end{array}$} & \multirow{2}{*}{$\begin{array}{l}\text { Phase } \\
\text { type }\end{array}$} & \multirow{2}{*}{\multicolumn{2}{|c|}{$\begin{array}{l}\mathrm{O} / \mathrm{H} \quad \mathrm{Z} \\
\text { ratio (f.u.) }\end{array}$}} & \multicolumn{3}{|c|}{ Lattice constants $(\AA)$} & \multirow{2}{*}{$\begin{array}{c}\mathrm{V} \\
\left(\AA^{3}\right)\end{array}$} & \multirow{2}{*}{$\begin{array}{l}\text { Density } \\
\left(\mathrm{g} / \mathrm{cm}^{3}\right)\end{array}$} & \multirow{2}{*}{$\begin{array}{c}\Delta E \\
(\mathrm{~kJ} / \mathrm{mol})\end{array}$} \\
\hline & & & & & & $\mathrm{a}$ & $b$ & $\mathrm{c}$ & & & \\
\hline 1 & $\mathrm{Y}_{4} \mathrm{H}_{10} \mathrm{O}$ & $P-43 m(215)$ & cubic & 0.1 & 1 & 5.230 & 5.230 & 5.230 & 143.03 & 4.43 & -1359.0 \\
\hline & $\mathrm{Y}_{2} \mathrm{H}_{4} \mathrm{O}$ & $P m(6)$ & $\begin{array}{l}\text { mono- } \\
\text { clinic }\end{array}$ & 0.25 & 1 & 3.677 & $\begin{array}{c}3.724 \\
\left(\beta=92.35^{\circ}\right)\end{array}$ & 5.409 & 74.00 & 4.44 & -847.4 \\
\hline & & $\mathrm{Cm}$ & $\begin{array}{l}\text { mono- } \\
\text { clinic }\end{array}$ & 0.25 & 2 & 6.368 & $\begin{array}{c}3.675 \\
\left(\beta=109.00^{\circ}\right)\end{array}$ & 6.537 & 144.65 & 4.54 & -870.1 \\
\hline 3 & $\mathrm{Y}_{2} \mathrm{H}_{3} \mathrm{O}$ & $P n-3 m(224)$ & cubic & 0.33 & 2 & 5.269 & 5.269 & 5.269 & 146.28 & 4.47 & -814.8 \\
\hline 4 & $\mathrm{Y}_{2} \mathrm{H}_{2} \mathrm{O}$ & P42/nnm (134) & tetragonal & 0.5 & 2 & 5.300 & 5.300 & 5.182 & 145.56 & 4.47 & -723.5 \\
\hline 5 & $\mathrm{Y}_{4} \mathrm{H}_{6} \mathrm{O}_{3}$ & $C m(8)$ & $\begin{array}{l}\text { mono- } \\
\text { clinic }\end{array}$ & 0.5 & 2 & 12.430 & $\begin{array}{c}3.843 \\
\left(\beta=99.37^{\circ}\right)\end{array}$ & 6.529 & 307.71 & 4.42 & -2148.1 \\
\hline & $\mathrm{Y}_{4} \mathrm{H}_{4} \mathrm{O}_{3}$ & $P-42 m(111)$ & tetragonal & 0.75 & 1 & 5.248 & 5.248 & 5.454 & 150.21 & 4.51 & -1978.9 \\
\hline & $F-43 m(216)$ & cubic & 1.00 & 4 & 5.292 & 5.292 & 5.292 & 148.20 & 4.75 & -661.5 \\
\hline & & Pnma & $\begin{array}{l}\text { ortho- } \\
\text { rhombic }\end{array}$ & 1.00 & 4 & 7.538 & .767 & 5.328 & 151.29 & 4.65 & -660.3 \\
\hline & & $R-3 m(166)$ & trigonal & 1.00 & 6 & 3.773 & 3.773 & 18.596 & 229.26 & 4.60 & -656.7 \\
\hline o & $\mathrm{Y}_{4} \mathrm{H}_{3} \mathrm{O}_{5}$ & $P-43 m(215)$ & cubic & 1.67 & 1 & 5.361 & 5.361 & 5.361 & 154.08 & 4.73 & -2785.2 \\
\hline 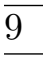 & $\mathrm{Y}_{2} \mathrm{HO}_{2}$ & $P-42 m(111)$ & tetragonal & 2.00 & 2 & 5.369 & 5.369 & 5.184 & 149.43 & 4.69 & -1186.5 \\
\hline 10 & $\mathrm{Y}_{4} \mathrm{H}_{2} \mathrm{O}_{5}$ & $P-42 m(111)$ & tetragonal & 2.50 & 1 & 5.364 & 5.364 & 5.319 & 153.04 & 4.75 & -2915.0 \\
\hline
\end{tabular}




$$
\begin{gathered}
1-\mathrm{Y}_{4} \mathrm{H}_{10} \mathrm{O} \\
2-\mathrm{Y}_{2} \mathrm{H}_{4} \mathrm{O} \\
3-\mathrm{Y}_{2} \mathrm{H}_{3} \mathrm{O} \\
4-\mathrm{Y}_{2} \mathrm{H}_{2} \mathrm{O} \\
5-\mathrm{Y}_{4} \mathrm{H}_{6} \mathrm{O}_{3} \\
6-\mathrm{Y}_{4} \mathrm{H}_{4} \mathrm{O}_{3} \\
7-\mathrm{YHO} \\
8-\mathrm{Y}_{4} \mathrm{H}_{3} \mathrm{O}_{5} \\
9-\mathrm{Y}_{2} \mathrm{HO}_{2} \\
10-\mathrm{Y}_{4} \mathrm{H}_{2} \mathrm{O}_{5}
\end{gathered}
$$

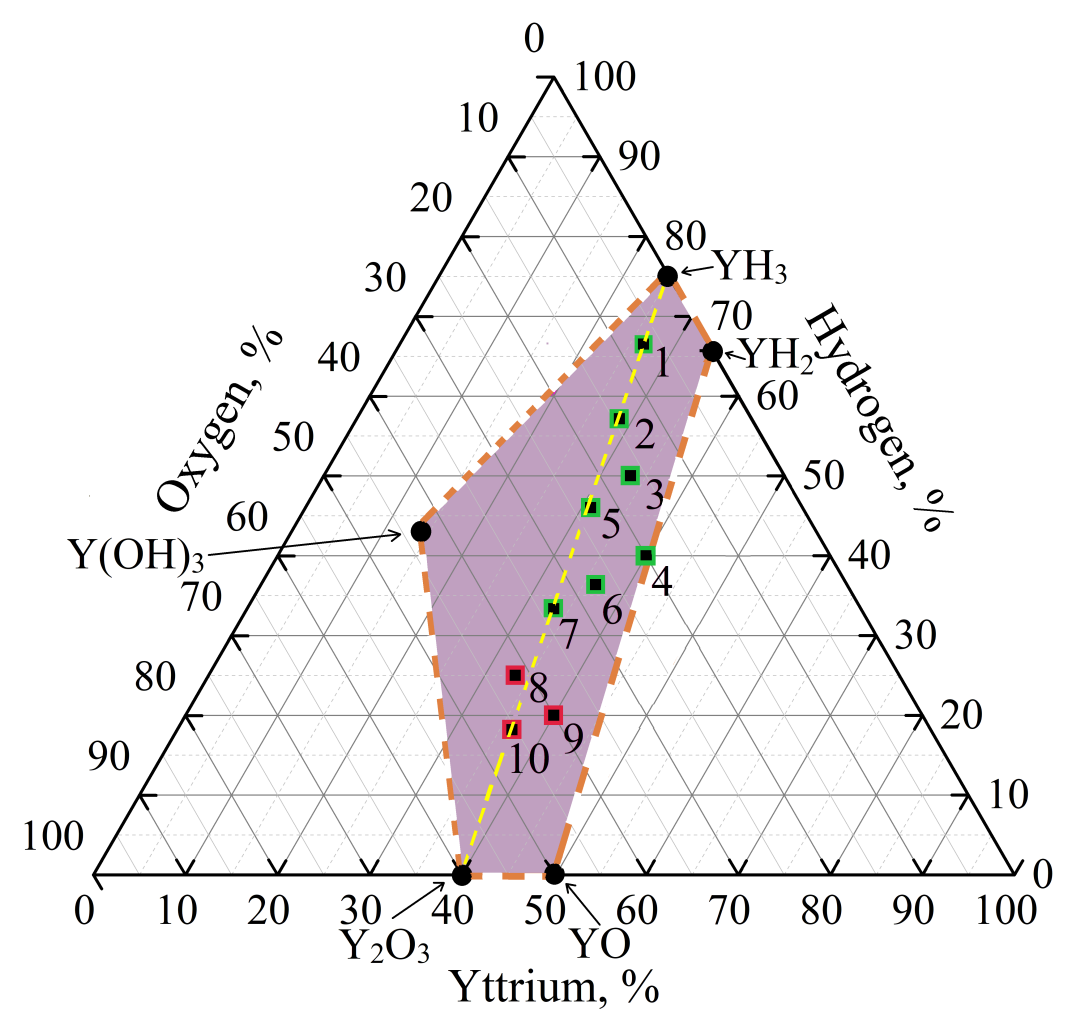

Figure 1: The $\mathrm{Y}-\mathrm{H}-\mathrm{O}$ triangle in terms of the $\mathrm{Y}, \mathrm{H}$, and $\mathrm{O}$ atomic variables: Phase diagram presenting the most probable equilibrium compositions which are marked by $\mathbf{\square}$ and numbered from 1 to 10 . The crystallographic description of predicted solid phases is given in Tables 1 and 2. The orange dashed lines connect such end members as $\mathrm{Y}_{2} \mathrm{O}_{3}, \mathrm{YO}, \mathrm{YH}_{2}, \mathrm{YH}_{3}$, and $\mathrm{Y}(\mathrm{OH})_{3}$. The union of their intersections shown as a solid pentagon represents the region of potential stability. The yellow dashed line connecting the end members $\mathrm{YH}_{3}$ and $\mathrm{Y}_{2} \mathrm{O}_{3}$ corresponds to a homologous series $\mathrm{Y}_{(2 \mathrm{n}+\mathrm{m}) / 3} \mathrm{H}_{\mathrm{m}} \mathrm{O}_{\mathrm{n}}$ (see text). Stoichiometries classified in Table 4 as stable and metastable are outlined by green and red edges, respectively.

The main our finding is that by simulating the oxygen-mediated structural evolution of the yttrium-hydride model we have predicted a large variety of crystalline phases for the $\mathrm{Y}-\mathrm{H}-\mathrm{O}$ system. Results presented in Figures $1-5$, and Tables $1-4$, encompass ten YxHyOz-type compositions comprising thirteen stoichiometric solid phases. The other details and datasets on the structural and physical properties of the predicted compounds are summarized in Supporting Information (SI). In particular, the information and criteria containing in Table S14 of SI (eigenvalues of the elasticity tensor), Tables S15 - S27 of SI (components of the elasticity tensor), and Tables S28 - S40 of SI (zone-centered har- 
Table 2: Overview of the shortest equilibrium interatomic distances evaluated for the crystal structures of Table 1. The last column presents a structural check on a total absence of the hydroxide anion.

\begin{tabular}{llcccc}
\hline $\begin{array}{l}\text { Chemical } \\
\text { formula }\end{array}$ & Structure & $\begin{array}{c}\mathrm{Y}-\mathrm{O} \\
(\AA)\end{array}$ & $\begin{array}{c}\mathrm{Y}-\mathrm{H} \\
(\AA)\end{array}$ & $\begin{array}{c}\mathrm{H}-\mathrm{H} \\
(\AA)\end{array}$ & $\begin{array}{c}\mathrm{O}-\mathrm{H} \\
(\AA)\end{array}$ \\
\hline $\mathrm{Y}_{4} \mathrm{H}_{10} \mathrm{O}$ & $P-43 m$ & 2.291 & 2.256 & 2.135 & 2.615 \\
\hline $\mathrm{Y}_{2} \mathrm{H}_{4} \mathrm{O}$ & $P m$ & 2.244 & 2.165 & 2.021 & 2.536 \\
\hline $\mathrm{Y}_{2} \mathrm{H}_{4} \mathrm{O}$ & $C m$ & 2.274 & 2.163 & 2.062 & 2.560 \\
\hline $\mathrm{Y}_{2} \mathrm{H}_{3} \mathrm{O}$ & $P n-3 m$ & 2.282 & 2.282 & 2.635 & 2.635 \\
\hline $\mathrm{Y}_{2} \mathrm{H}_{2} \mathrm{O}$ & $P 42 / n n m$ & 2.278 & 2.278 & 2.591 & 2.650 \\
\hline $\mathrm{Y}_{4} \mathrm{H}_{6} \mathrm{O}_{3}$ & $C m$ & 2.150 & 2.242 & 2.128 & 2.488 \\
\hline $\mathrm{Y}_{4} \mathrm{H}_{4} \mathrm{O}_{3}$ & $P-42 m$ & 2.216 & 2.277 & 2.727 & 2.624 \\
\hline $\mathrm{YHO}$ & $F-43 m$ & 2.292 & 2.292 & 3.742 & 3.742 \\
\hline $\mathrm{YHO}$ & $P n m a$ & 2.243 & 2.307 & 2.428 & 2.679 \\
\hline $\mathrm{YHO}$ & $R-3 m$ & 2.245 & 2.305 & 2.532 & 2.679 \\
\hline $\mathrm{Y}_{4} \mathrm{H}_{3} \mathrm{O}_{5}$ & $P-43 m$ & 2.207 & 2.362 & 3.791 & 2.681 \\
\hline $\mathrm{Y}_{2} \mathrm{HO}_{2}$ & $P-42 m$ & 2.353 & 2.340 & 3.796 & 2.592 \\
\hline $\mathrm{Y}_{4} \mathrm{H}_{2} \mathrm{O}_{5}$ & $P-42 m$ & 2.204 & 2.319 & 3.793 & 2.660 \\
\hline
\end{tabular}

monic vibrational modes) confirm structural stability of the systems listed in Table 1 . The entry $\mathrm{No}_{1}, \mathrm{Y}_{4} \mathrm{H}_{10} \mathrm{O}$, was suggested and characterized in our previous work. ${ }^{9}$ Here, its structure has been adjusted to noncentrosymmetric space group $P-43 m$, and properties have been re-investigated in more detail. A noteworthy result is that our comparative analysis of experimental XRD patterns of the transparent-semiconducting $\mathrm{Y}-\mathrm{H}-\mathrm{O}$ thin films ${ }^{2}$ leads to a suggestion that these films may be regarded as having the composition $\mathrm{Y}_{4} \mathrm{H}_{10} \mathrm{O}$ and adopting the cubic $P-43 m$ structure.

The comprehensive analysis of macroscopic elastic and plastic properties is presented in Table 3. One can see that these properties closely resemble those observed for typical ion-covalent or metallic materials. However, regardless of the similarity of aggregate characteristics the predicted structures demonstrate the interesting feature relating to the magnitude of the Grüneisen parameter, which turns out to be markedly high for the oxyhydrides with the metal ground state (Table 3). Obviously, this fact reflects the characteristic anharmonic interactions, which are operative because the amount of incorporated oxygen atoms is still yet insufficient to shield strong quantum-mechanical movements of hydrogen. 
Table 3: Aggregate properties evaluated for the crystal structures of Table 1. The bulk $(B)$, shear $(G)$, and Young's $(E)$ moduli are given in the Hill approximation. ${ }^{10}$ The relation $G / B$ denotes Pugh's ratio, and $\nu$ is Poisson's ratio. The Grüneisen parameter $(\gamma)$ and the Debye temperature $\left(\Theta_{D}\right)$ have been estimated within semi-empirical approaches of Refs. 11 and 12 , respectively. The values of the Vickers hardness $H_{V}$ have been evaluated from the model relations of Refs. 13,14. The abbreviations: ins=insulator, met=metal.

\begin{tabular}{llccccccccc}
\hline $\begin{array}{l}\text { Chemical } \\
\text { formula }\end{array}$ & Structure & $\begin{array}{c}\text { Ground } \\
\text { state }\end{array}$ & $\begin{array}{c}B \\
(\mathrm{GPa})\end{array}$ & $\begin{array}{c}E \\
(\mathrm{GPa})\end{array}$ & $\begin{array}{c}G \\
(\mathrm{GPa})\end{array}$ & $G / B$ & $\nu$ & $\gamma$ & $\begin{array}{c}\Theta_{D} \\
(\mathrm{~K})\end{array}$ & $\begin{array}{c}H_{V} \\
(\mathrm{GPa})\end{array}$ \\
\hline $\mathrm{Y}_{4} \mathrm{H}_{10} \mathrm{O}$ & $P-43 m$ & ins & 97.8 & 170.6 & 70.6 & 0.72 & 0.21 & 1.83 & 619 & $13.5 / 12.9$ \\
\hline $\mathrm{Y}_{2} \mathrm{H}_{4} \mathrm{O}$ & $P m$ & ins & 78.7 & 127.3 & 51.7 & 0.66 & 0.23 & 2.15 & 513 & $9.3 / 9.3$ \\
\hline $\mathrm{Y}_{2} \mathrm{H}_{4} \mathrm{O}$ & $C m$ & ins & 94.1 & 151.0 & 61.2 & 0.65 & 0.23 & 2.18 & 556 & $10.4 / 10.4$ \\
\hline $\mathrm{Y}_{2} \mathrm{H}_{3} \mathrm{O}$ & $P n-3 m$ & met & 101.4 & 134.5 & 52.6 & 0.52 & 0.28 & 3.18 & 494 & $6.4 / 7.2$ \\
\hline $\mathrm{Y}_{2} \mathrm{H}_{2} \mathrm{O}$ & $P 42 / n n m$ & met & 92.6 & 117.8 & 45.7 & 0.49 & 0.29 & 3.44 & 435 & $5.2 / 6.2$ \\
\hline $\mathrm{Y}_{4} \mathrm{H}_{6} \mathrm{O}_{3}$ & $C m$ & ins & 97.8 & 127.6 & 49.7 & 0.51 & 0.28 & 3.29 & 488 & $5.9 / 6.8$ \\
\hline $\mathrm{Y}_{4} \mathrm{H}_{4} \mathrm{O}_{3}$ & $P-42 m$ & met & 99.3 & 140.6 & 55.6 & 0.56 & 0.26 & 2.81 & 486 & $7.6 / 8.2$ \\
\hline $\mathrm{YHO}$ & $F-43 m$ & ins & 125.3 & 187.2 & 74.8 & 0.60 & 0.25 & 2.52 & 567 & $10.7 / 10.9$ \\
\hline $\mathrm{YHO}$ & $P n m a$ & ins & 117.5 & 168.1 & 66.6 & 0.57 & 0.26 & 2.74 & 538 & $9.0 / 9.4$ \\
\hline $\mathrm{YHO} \mathrm{HO}$ & $R-3 m$ & ins & 110.2 & 149.8 & 58.8 & 0.53 & 0.27 & 3.03 & 507 & $7.4 / 8.1$ \\
\hline $\mathrm{Y}_{4} \mathrm{H}_{3} \mathrm{O}_{5}$ & $P-43 m$ & met & 117.7 & 146.9 & 56.8 & 0.48 & 0.29 & 3.57 & 492 & $6.1 / 7.0$ \\
\hline $\mathrm{Y}_{2} \mathrm{HO}_{2}$ & $P-42 m$ & met & 108.5 & 146.5 & 57.5 & 0.53 & 0.27 & 3.07 & 471 & $7.2 / 7.9$ \\
\hline $\mathrm{Y}_{4} \mathrm{H}_{2} \mathrm{O}_{5}$ & $P-42 m$ & ins & 99.5 & 126.9 & 49.3 & 0.50 & 0.29 & 3.43 & 444 & $5.6 / 6.5$ \\
\hline
\end{tabular}

Table 4: Decomposition reaction enthalpy $\Delta H_{0}$ calculated for the crystal structures of Table 1.

\begin{tabular}{lllc}
\hline $\begin{array}{l}\text { Chemical } \\
\text { formula }\end{array}$ & Structure & $\begin{array}{l}\text { Decomposition } \\
\text { products }\end{array}$ & $\begin{array}{c}\Delta H_{0} \\
(\mathrm{~kJ} / \mathrm{mol})\end{array}$ \\
\hline $\mathrm{Y}_{4} \mathrm{H}_{10} \mathrm{O}$ & $P-43 m$ & $\mathrm{Y}_{2} \mathrm{O}_{3}, \mathrm{YH}_{3}$ & -250.2 \\
\hline $\mathrm{Y}_{2} \mathrm{H}_{4} \mathrm{O}$ & $P m$ & $\mathrm{Y}_{2} \mathrm{O}_{3}, \mathrm{YH}_{3}$ & -58.9 \\
\hline $\mathrm{Y}_{2} \mathrm{H}_{4} \mathrm{O}$ & $C m$ & $\mathrm{Y}_{2} \mathrm{O}_{3}, \mathrm{YH}_{3}$ & -81.7 \\
\hline $\mathrm{Y}_{2} \mathrm{H}_{3} \mathrm{O}$ & $P n-3 m$ & $\mathrm{Y}_{2} \mathrm{O}_{3}, \mathrm{YH}_{3}, \mathrm{Y}$ & -79.9 \\
\hline $\mathrm{Y}_{2} \mathrm{H}_{2} \mathrm{O}$ & $P 42 / n n m$ & $\mathrm{Y}_{2} \mathrm{O}_{3}, \mathrm{YH}_{3}, \mathrm{Y}$ & -41.7 \\
\hline $\mathrm{Y}_{4} \mathrm{H}_{6} \mathrm{O}_{3}$ & $C m$ & $\mathrm{Y}_{2} \mathrm{O}_{3}, \mathrm{YH}_{3}$ & -102.7 \\
\hline $\mathrm{Y}_{4} \mathrm{H}_{4} \mathrm{O}_{3}$ & $P-42 m$ & $\mathrm{Y}_{2} \mathrm{O}_{3}, \mathrm{YH}_{3}, \mathrm{Y}$ & -40.7 \\
\hline $\mathrm{YHO}$ & $F-43 m$ & $\mathrm{Y}_{2} \mathrm{O}_{3}, \mathrm{YH}_{3}$ & -33.1 \\
\hline $\mathrm{YHO}$ & $P n m a$ & $\mathrm{Y}_{2} \mathrm{O}_{3}, \mathrm{YH}_{3}$ & -31.9 \\
\hline $\mathrm{YHO} \mathrm{O}-3 m$ & $\mathrm{Y}_{2} \mathrm{O}_{3}, \mathrm{YH}_{3}$ & -28.3 \\
\hline $\mathrm{Y}_{4} \mathrm{H}_{3} \mathrm{O}_{5}$ & $P-43 m$ & $\mathrm{Y}_{2} \mathrm{O}_{3}, \mathrm{YH}_{3}, \mathrm{H}_{2}$ & +197.1 \\
\hline $\mathrm{Y}_{2} \mathrm{HO} \mathrm{O}_{2}$ & $P-42 m$ & $\mathrm{Y}_{2} \mathrm{O}_{3}, \mathrm{YH}_{3}, \mathrm{Y}$ & +16.9 \\
\hline $\mathrm{Y}_{4} \mathrm{H}_{2} \mathrm{O}_{5}$ & $P-42 m$ & $\mathrm{Y}_{2} \mathrm{O}_{3}, \mathrm{YH}_{3}$ & +66.4 \\
\hline
\end{tabular}

The examination of formation energies (shown in the last column of Table 1) indicates that the structures of ternary oxyhydrides are enthalpically stable with respect to the decomposition into the simple elements. Further investigation of the energetics of spontaneous 
decomposition into the binary products is outlined in Table 4. To determine which indicators may be critical to the chemical stability we performed a comparative analysis of the compositional representations of the phase diagram. First, by laying out the possible superpositions and intersections of the main decomposition trends we assigned the common area of potential stability which is schematically given by a solid pentagon in Figure 1 . It is noteworthy that such configuration of the composition domain compiled in terms of decomposition constraints has brought together all the chemical formulas derived in the present work by means of crystal chemical modeling and DFT-based simulations. Clearly, this fact confirms the full consistency of our results. Moreover, as it was revealed in Ref. 15, the yellow dashed line in Figure 1 corresponds to the array of condensed phases with the composition range obeying the chemical formula of a homologous series $\mathrm{Y}_{(2 \mathrm{n}+\mathrm{m}) / 3} \mathrm{H}_{\mathrm{m}} \mathrm{O}_{\mathrm{n}}$, where $n$ and $m$ are integer numbers.

Secondly, both experiments and theoretical results show that oxygen is readily incorporated into the metal-hydride system in noticeable amounts. It appears from Figure 2 that the formation of oxyhydride phases is accompanied by the lattice expansion which begins to grow continuously already at low oxygen content. This expansion can be attributed to a tendency observed in a number of compositions for $\mathrm{Y}-\mathrm{O}$ separation to increase gradually with the rising $\mathrm{O} / \mathrm{H}$ ratio (bottom plot of Figure 2). One can see that incorporation of more oxygen does not destroy the linear behavior of both trends, but makes the $\mathrm{Y}-\mathrm{O}$ bonding weaker by elongating the distance between $\mathrm{Y}$ and $\mathrm{O}$. Thus, in a simplified picture of the lattice geometries, just the strong effect of symmetry-lowering oxygen and hydrogen displacements may be thought of as holding the general patterns of the oxyhydride phase structurally stable. However, at high oxygen content, the overall strengths of the actual binding interactions become weaker since the relevant calculations have demonstrated that the oxyhydride system does become metastable with respect to the solid-phase decomposition.

Thirdly, although with decreasing hydrogen content the $\mathrm{Y} / \mathrm{H}$ ratio can vary from 0.4 to 2 across the range of the ternary compositions considered, just the case of $\mathrm{Y} / \mathrm{H}=1$ is of 


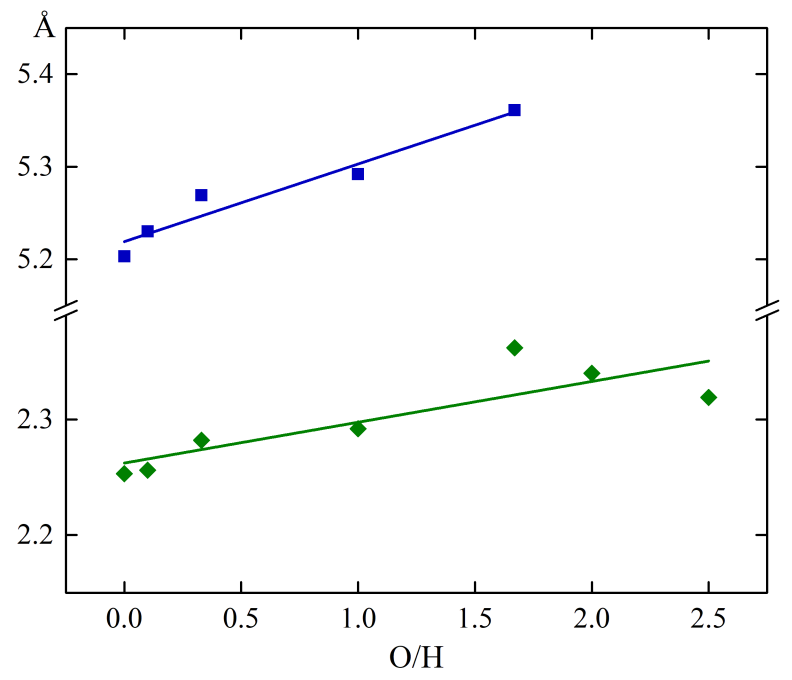

Figure 2: The $\mathrm{Y}-\mathrm{O}$ separation (bottom plot in dark green), and the lattice expansion illustrated for the case of cubic phases (top plot in dark blue) versus the $\mathrm{O} / \mathrm{H}$ ratio. The data points are from Tables 1 and 2. The solid lines represent a linear regression. The zero point corresponds to the cubic $\mathrm{YH}_{2}$ with $a=5.203 \AA .{ }^{16}$

frequent occurrence. The effect of sensitivity to $\mathrm{H}$ correlates directly with the considerable elongation of the $\mathrm{Y}-\mathrm{H}$ bond distances (i.e., weakening of the metal-hydrogen bond upon oxidation process), as illustrated in Table 2 for the trend of predicted geometries. According to the data of Table 4, the crystallization of chemical compositions with the particular $\mathrm{Y} / \mathrm{H}$ and $\mathrm{O} / \mathrm{H}$ ratios greater than 1 (i.e., when an extended oxygen content makes a hydrogen amount in the composition smaller than the relevant amounts of yttrium and oxygen), leads to the formation of metastable and mostly soft crystal structures. Therefore, these ratios may be considered as critical indicators of the composition effect which places certain restrictions on the phase stability of ternary compounds in terms of the following inequalities: $\mathrm{Y} / \mathrm{H}>1$ and $1<\mathrm{O} / \mathrm{H}<5 / 3$. These inequalities determine the area where the upper boundary of the stability can be found. Illustratively, stability-metastability sharing scheme is shown in Figure 3 .

Another specific correlation is the minimum $\mathrm{H}-\mathrm{H}$ separation (Table 2) which satisfies Switendicks criterion $^{17}(>2.1 \AA)$ for the most compositions and crystal structures except for monoclinic phases of the hydrogen-rich $\mathrm{Y}_{2} \mathrm{H}_{4} \mathrm{O}$. Evidently, the reason for such shortening 


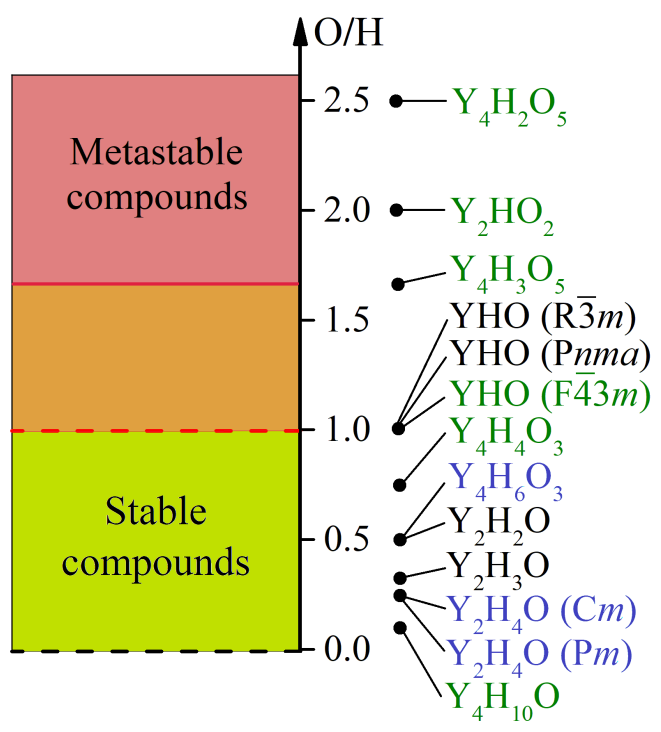

Figure 3: Illustrative separation scheme for yttrium oxyhydrides. Pyroelectric phases are shown in blue, the systems without inversion center are shown in green. The light-browncolored rectangular box separates into the stable (below) and metastable (above) compounds. The box offset is limited to the point $\mathrm{O} / \mathrm{H}=5 / 3$.

of $\mathrm{H}-\mathrm{H}$ spacings is related to a particular low-symmetry structure in which the equilibrium local configuration of coordinating yttrium and neighboring hydrogens matches the enhanced repulsive character of $\mathrm{H}-\mathrm{H}$ interactions via the enhancement of the metal-hydrogen coupling.

Figure 4 shows the predicted compounds. The crystal structures of these compounds range through high-symmetry to low-symmetry lattice geometries, and exhibit the different levels of stability. Some of them demonstrate more complex solid state constitution in terms of such characteristic factors as coordination of $\mathrm{Y}-\mathrm{H}$ and $\mathrm{Y}-\mathrm{O}$ groups, layers configuration, and stacking sequences. As highlighted in Table 4, hydrogen-poor ternary compositions are metastable with respect to the decomposition to the binary compounds. On the base of the valence electron counts and DFT calculations one can verify that depending on the $\mathrm{O} / \mathrm{H}$ ratio, the ground state of these structures exhibits either insulating or metallic character. It is interesting to note the polymorphism feature exhibiting by YHO: its crystallization enables three different crystalline modifications, namely the cubic AgAsMg-type ${ }^{18}(F-43 m)$, the orthorhombic TiNiSi-type ${ }^{19}$ (Pnma), and the trigonal SmSI-type ${ }^{20}(R-3 m)$ forms of the 


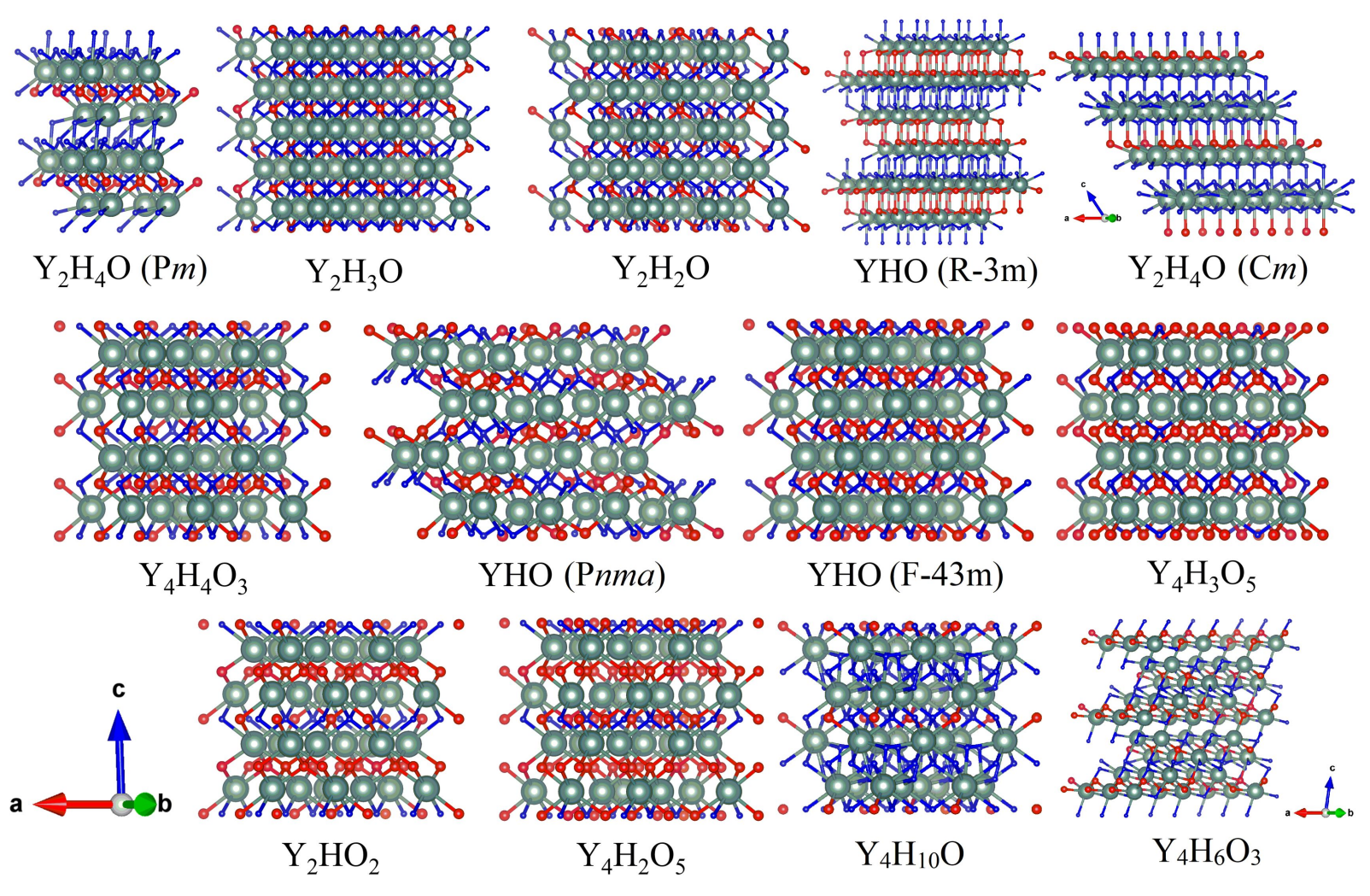

Figure 4: Comparison of the crystal structures predicted for different compositions of yttrium oxyhydride. $\mathrm{Y}$ - green, $\mathrm{H}$ - blue, and $\mathrm{O}$ - red spheres.

lattice structure. Comparison shows that the cubic F-43m phase of YHO is the most stable. In the context of the phase diagram, we have made a reconciliation analysis to examine a structural investigation presented in Ref. 3 for thin film samples of oxygen-containing yttrium hydride. In Figure 5, the synchrotron X-ray diffraction pattern is compared with the theoretical one calculated for the F-43m crystal structure. A good match of both results provides a clear conclusion that the synthesized material ${ }^{3}$ has the chemical formula YHO, and its crystalline structure perfectly corresponds to the cubic space group F-43m. This is important indication that a lowering of space group symmetry as compared with the $F m$-3m structure of the bulk $\mathrm{YH}_{2}$ results from the parent structure change which is needed to ensure stability of new ordering patterns of the oxide and hydride ions in the oxyhydride system.

Another important result emphasized in Figures 3 and 4 is an appearance of noncen- 


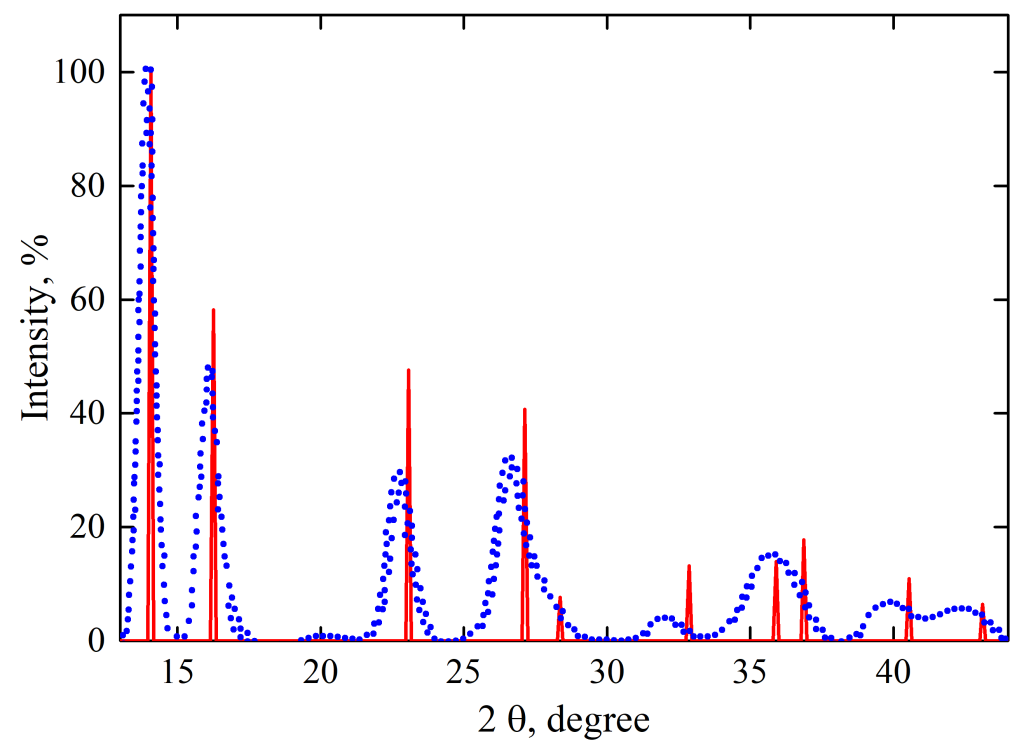

Figure 5: Comparison of the SR-XRD measurement of the thin film samples ${ }^{3}$ of oxygencontaining yttrium hydride (plotted in blue) with the theoretical calculations of the XRD profile (shown in red) for the $F-43 m$ crystal structure of the YHO composition.

trosymmetric systems in the family of yttrium oxyhydrides. In this context, it is particularly remarkable that our modeling approach has been so general to offer direct control of inversion symmetry in the course of structural transformations. Evidently, the lack of central symmetry at the macroscopic scale is caused by the interplay of the mixed-anion chemistry and the multilattice periodic structure: that is, when compositional order that destroys the inversion center through a mismatch of the different $\mathrm{H}^{-}$and $\mathrm{O}^{2-}$ anion sublattice positions becomes energetically favorable. For example, the stable composition $\mathrm{Y}_{2} \mathrm{H}_{4} \mathrm{O}$ favors crystallization into two polymorphic modifications relating to polar space groups $\mathrm{Cm}$ and $\mathrm{Pm}$, respectively. The other fascinating case indicated in Figure 4 relates to the prediction of the metallic material containing oxygen $\mathrm{Y}_{4} \mathrm{H}_{4} \mathrm{O}_{3}$, which crystallizes in the noncentrosymmetric tetragonal $P-42 m$ structure. Note that metals with broken inversion symmetry attract a lot of attention due to unconventional features caused by the cross-effect of acentric displacements and macroscopic metallic properties. ${ }^{21,22}$

In summary, the most attractive side of modeling and simulation of a mixed-anion system is the possibility to use the interplay of different anions to expand the functional properties 
of a simple binary hydride. In this aspect, the difference between hydrogen and oxygen associated with electronegativity values, atom sizes, orbital properties, and the corresponding yttrium affinities is of particular importance. In the present work, the predictive potential of the theory-driven modeling has been employed to predict the structure and to describe the structural properties of yttrium oxyhydrides. First, the central emphasis was placed on the elaboration of the phase diagram because its knowledge allows one to understand the synthesis and crystallization of the most favorable compositions, and to control the phase transformations that may accompany the formation process. Secondly, our description of the possible crystallizations in the $\mathrm{Y}-\mathrm{H}-\mathrm{O}$ system has proved the stabilization role of oxygen in formation of the anionic framework for the various lattice geometries. Finally, the practical importance our work is that we presented the detail information on solid phases and symmetries for the different crystalline forms of yttrium oxyhydrides.

\section{Methods}

\section{Computational details}

Periodic electron structure calculations have been performed within density functional theory by using Vienna ab initio simulation package ${ }^{23}$ (VASP) with the potential projector augmented-wave method $^{24,25}$ (PAW). One-electron energies were evaluated on the base of Perdew-Burke-Ernzerhof (PBE) GGA exchange-correlation functional, ${ }^{26}$ and the PAW-PBE pseudo-potentials. The plane-wave basis sets corresponded to $4 s^{2} 4 p^{6} 5 s^{2} 4 d^{1}, 2 s^{2} 2 p^{4}$, and $1 s^{1}$ valence electron configurations for $\mathrm{Y}, \mathrm{O}$, and $\mathrm{H}$ elements, respectively. Plane-wave energy cutoffs of $700 \mathrm{eV}$, and the Brillouin-zone sampling in terms of the $8 \times 8 \times 8 \mathrm{k}$-point mesh have been used to provide well-converged total-energy results with the degree of accuracy below $1 \mathrm{meV} /($ unit cell). In the crystal structure calculations, the equilibrium lattice parameters and internal atomic positions were fully optimized for all geometries. 


\section{Structural evolution, compositional optimization, and post-processing analysis}

Cubic lattice of the $F m \overline{3} m$ symmetry was chosen as a crystalline template for structural evolutions. To account for the activity of atoms in the oxidation process, and to address a compositional optimization governed by oxygen incorporation, a set of packing configurations was subjected to different oxygen distributions. The screening of structures were performed on the base of the Bärnighausen tree ${ }^{27}$ for several sequences of lattice transformations. The ways of crystal symmetry lowering were outlined in terms of the group-subgroup relations; the relations were constructed by means of the program tools ${ }^{28}$ hosted by Bilbao Crystallographic Server. ${ }^{29,30}$ The ISOTROPY software suite ${ }^{31,32}$ and the VESTA program ${ }^{33}$ have been applied for the determination of the probable crystal structures. Visualizations have been also made by means of the VESTA program. The formation energy (the heat of formation at $T=0$ $\mathrm{K}$ ) was estimated in a standard way in terms of the difference between the ground-state energy per formula unit and the sum of the corresponding energies of constituent elements. Evaluation of the elastic properties was performed by means of the ELATE online tool. ${ }^{34}$

\section{Acknowledgement}

A.P. was supported by institutional research funding IUT2-27 of the Estonian Ministry of Education and Research. E.S. was supported by Dora Plus PhD student mobility grant (T1.2). Part of the calculations has been performed by using facilities of the Notur supercomputing center.

\section{Supporting Information Available}

Theoretical predictions for structural properties of yttrium oxyhydrides: optimized results of equilibrium atomic positions, eigenvalues of the stiffness matrix, zone-centered harmonic vibrational modes, and images of X-ray diffraction patterns. 


\section{References}

(1) Mongstad, T.; Platzer-Björkman, C.; Maehlen, J. P.; Mooij, L. P.; Pivak, Y.; Dam, B.; Marstein, E. S.; Hauback, B. C.; Karazhanov, S. Z. Solar Energy Materials and Solar Cells 2011, 95, 3596-3599.

(2) Montero, J.; Martinsen, F. A.; García-Tecedor, M.; Karazhanov, S. Z.; Maestre, D.; Hauback, B.; Marstein, E. S. Phys. Rev. B 2017, 95, 201301.

(3) Maehlen, J. P.; Mongstad, T. T.; You, C. C.; Karazhanov, S. J. Alloys Compd. 2013, 580, S119-S121.

(4) Chandran, C. V.; Schreuders, H.; Dam, B.; Janssen, J. W. G.; Bart, J.; Kentgens, A. P. M.; van Bentum, P. J. M. The Journal of Physical Chemistry C 2014, 118, 2293522942.

(5) (a) You, C. C.; Moldarev, D.; Mongstad, T.; Primetzhofer, D.; Wolff, M.; Marstein, E. S.; Karazhanov, S. Z. Solar Energy Materials and Solar Cells 2017, 166, 185 - 189; (b) Moldarev, D.; Primetzhofer, D.; You, C. C.; Karazhanov, S. Z.; Montero, J.; Martinsen, F.; Mongstad, T.; Marstein, E. S.; Wolff, M. Solar Energy Materials and Solar Cells 2018, 177, $66-69$.

(6) Nafezarefi, F.; Schreuders, H.; Dam, B.; Cornelius, S. Applied Physics Letters 2017, $111,103903$.

(7) (a) Yamamoto, T.; Kageyama, H. Chemistry Letters 2013, 42, 946-953; (b) Kobayashi, Y.; Hernandez, O.; Tassel, C.; Kageyama, H. Science and Technology of Advanced Materials 2017, 18, 905-918, PMID: 29383042; (c) Kobayashi, Y.; Tsujimoto, Y.; Kageyama, H. Annual Review of Materials Research 2018, 48, 303-326; (d) Kageyama, H.; Hayashi, K.; Maeda, K.; Attfield, J. P.; Hiroi, Z.; Rondinelli, J. M.; Poeppelmeier, K. R. Nature Communications 2018, 9. 
(8) (a) Pishtshev, A. Inorganic Chemistry 2017, 56, 10815-10823; (b) Pishtshev, A.; Rubin, P. Physical Review B 2016, 93; (c) Pishtshev, A.; Karazhanov, S. Z. The Journal of Chemical Physics 2017, 146, 064706.

(9) Pishtshev, A.; Karazhanov, S. Z. Solid State Communications 2014, 194, 39 - 42.

(10) Hill, R. Proceedings of the Physical Society. Section A 1952, 65, 349.

(11) Belomestnykh, V. N.; Tesleva, E. P. Technical Physics 2004, 49, 1098-1100.

(12) Anderson, O. L. Journal of Physics and Chemistry of Solids 1963, 24, 909 - 917.

(13) Chen, X.-Q.; Niu, H.; Li, D.; Li, Y. Intermetallics 2011, 19, 1275 - 1281.

(14) Tian, Y.; Xu, B.; Zhao, Z. International Journal of Refractory Metals and Hard Materials 2012, 33, $93-106$.

(15) Pishtshev, A.; Strugovshchikov, E. On compositional homology of stoichiometric oxyhydryde phases of three-valence metals (to be published).

(16) Wang, Y.; Chou, M. Y. Physical Review B 1994, 49, 10731-10734.

(17) (a) Switendick, A. C. Zeitschrift für Physikalische Chemie 1979, 117, 89-112; (b) Rao, B. K.; Jena, P. Physical Review B 1985, 31, 6726-6730.

(18) Sibert, W.; Nowotny, H. Zeitschrift fuer Metallkunde 1941, 33, 391-394.

(19) Jeitschko, W. Acta Crystallographica Section B Structural Crystallography and Crystal Chemistry 1968, 24, 930-934.

(20) Savigny, N.; Laruelle, P.; Flahaut, J. Acta Crystallographica Section B Structural Crystallography and Crystal Chemistry 1973, 29, 345-347.

(21) (a) Mineev, V. P.; Yoshioka, Y. Physical Review B 2010, 81, 094525; (b) Edelstein, V. M. Physical Review B 2011, 83, 113109. 
(22) (a) Puggioni, D.; Rondinelli, J. M. Nature Communications 2014, 5; (b) Puggioni, D.; Giovannetti, G.; Capone, M.; Rondinelli, J. M. Physical Review Letters 2015, 115, 087202.

(23) (a) Kresse, G.; Furthmüller, J. Computational Materials Science 1996, 6, 15-50; (b) Kresse, G.; Furthmüller, J. Phys. Rev. B 1996, 54, 11169-11186.

(24) Blöchl, P. E. Phys. Rev. B 1994, 50, 17953-17979.

(25) Kresse, G.; Joubert, D. Phys. Rev. B 1999, 59, 1758-1775.

(26) Perdew, J. P.; Burke, K.; Ernzerhof, M. Phys. Rev. Lett. 1996, 77, 3865-3868.

(27) (a) Bärnighausen, H. MATCH Commun. Math. Chem. 1980, 9, 139-175; (b) Köhler, K. J. MATCH Commun. Math. Chem. 1980, 9, 191-207.

(28) (a) Ivantchev, S.; Kroumova, E.; Madariaga, G.; Pérez-Mato, J. M.; Aroyo, M. I. Journal of Applied Crystallography 2000, 33, 1190-1191; (b) Kroumova, E.; Aroyo, M. I.; Pérez-Mato, J. M.; Kirov, A.; Capillas, C.; Ivantchev, S.; Wondratschek, H. Phase Transitions 2003, 76, 155-170.

(29) Bilbao Crystallographic Server. http://www.cryst.ehu.es.

(30) (a) Aroyo, M.; Pérez-Mato, J.; Orobengoa, D.; Tasci, E.; de la Flor, G.; Kirov, A. Bulg. Chem. Commun. 2011, 43, 183-197; (b) Aroyo, M.; Pérez-Mato, J.; Capillas, C.; Kroumova, E.; Ivantchev, S.; Madariaga, G.; Kirov, A.; Wondratschek, H. Z. Krist. 2006, 221, 15-27; (c) Aroyo, M. I.; Kirov, A.; Capillas, C.; Pérez-Mato, J. M.; Wondratschek, H. Acta Cryst. 2006, A62, 115-128.

(31) Stokes, H. T.; Hatch, D. M.; Campbell, B. J. ISOTROPY Software Suite. http:// stokes.byu.edu/iso/isotropy.php.

(32) Stokes, H. T.; Hatch, D. M. Journal of Applied Crystallography 2005, 38, 237-238. 
(33) Momma, K.; Izumi, F. Journal of Applied Crystallography 2011, 44, 1272-1276.

(34) (a) Gaillac, R.; Pullumbi, P.; Coudert, F.-X. Journal of Physics: Condensed Matter 2016, 28, 275201; (b) Gaillac, R.; Coudert, F.-X. ELATE: Elastic tensor analysis. http://progs. coudert. name/elate. 